\title{
The Effects of Entrepreneurship on the Enterprises' Sustainable Innovation Capability in the Digital Era: The Role of Organizational Commitment, Person-Organization Value Fit, and Perceived Organizational Support
}

\author{
Donghui Zhao ${ }^{1}$, Feng Tian ${ }^{2, * \mathbb{D}}$, Xinbo Sun ${ }^{1}$ and Dapeng Zhang ${ }^{3}$ \\ 1 School of Business Administration, Northeastern University, Shenyang 110169, China; \\ donghui.zhao@xyleminc.com (D.Z.); xbsun@mail.neu.edu.cn (X.S.) \\ 2 Lecturer in International Business, School of Business and Law, University of Newcastle Australia, \\ Newcastle, NSW 2307, Australia \\ 3 Lecturer in Management, School of Economics and Management, China University of Mining and \\ Technology, Xuzhou 221116, China; dpzhang@cumt.edu.cn \\ * Correspondence: feng.tian@newcastle.edu.au; Tel.: +61-(602)-49215981
}

\section{check for} updates

Citation: Zhao, D.; Tian, F.; Sun, X.; Zhang, D. The Effects of

Entrepreneurship on the Enterprises' Sustainable Innovation Capability in the Digital Era: The Role of

Organizational Commitment,

Person-Organization Value Fit, and Perceived Organizational Support. Sustainability 2021, 13, 6156.

https://doi.org/10.3390/su13116156

Academic Editor: Fernando Almeida

Received: 4 May 2021

Accepted: 28 May 2021

Published: 30 May 2021

Publisher's Note: MDPI stays neutral with regard to jurisdictional claims in published maps and institutional affiliations.

Copyright: (c) 2021 by the authors. Licensee MDPI, Basel, Switzerland. This article is an open access article distributed under the terms and conditions of the Creative Commons Attribution (CC BY) license (https:/ / creativecommons.org/licenses/by/ $4.0 /)$.

\begin{abstract}
The concept of entrepreneurship in the digital era has been developed rapidly in recent years, and it has a more significant impact on a company's sustainable innovation capabilities. In the digital era, entrepreneurship has gradually become a spiritual trait of organization members and appears on all levels of an organization. This research examines the impact of entrepreneurship on a company's sustainable innovation capability in the digital era from the perspective of organizational commitment. Through a questionnaire survey, 378 valid questionnaires were collected. The results show that: entrepreneurship has a positive impact on sustainable innovation capability of enterprises; affective commitment plays a positive mediating role between entrepreneurship and enterprises' sustainable innovation capability, while continuance commitment plays a negative mediating role between entrepreneurship and enterprises' sustainable innovation capability; and perceived organizational support and person-organization value fit play a moderating role between entrepreneurship and organizational commitment. This article emphasizes the key role of entrepreneurship on enterprises' sustainable innovation capability and discusses the realization path of the enterprises' sustainable innovation capability from the perspective of organizational commitment.
\end{abstract}

Keywords: digital era; entrepreneurship; organizational commitment; perceived organizational support; person-organization value fit; enterprises' sustainable innovation capability

\section{Introduction}

Sustainability and digitalization are the main trends shaping the economy and society [1]. Digitalization is considered to be an important factor in achieving sustainable development of enterprises [2,3]. In particular, with the support of relevant technologies such as big data and artificial intelligence, enterprises can quickly respond to external demands and make timely strategic adjustments [4-6]. Both large and small organizations are trying to take digital innovation as the cornerstone of their continuous value creation, hoping to realize the dynamic value creation process [6,7]. Digitization breaks down the boundaries between the different stages of product introduction to the market and brings a greater degree of unpredictability and nonlinearity to their development [8]. In order to meet the basic requirements of sustainable innovation, more and more enterprises authorize decision-making power to their employees by adjusting the organizational structure and reducing the organizational hierarchy [9]. Compared with traditional organizational models, more implicit innovation responsibility behaviors that used to belong to employees in the past are aroused by the platform organizational model $[9,10]$. 
Employees are becoming the key players in identifying potential market opportunities, making accurate strategic decision, and providing service value to customers [11]. As a spiritual trait, entrepreneurship exists in internet organization $[8,10,12]$. Once, the famous economy scholar of Austrian schools De Soto said, "The purest form of entrepreneurship is ubiquitous"; that means everyone in the market has entrepreneurship, which is not an ability possessed by some certain talents but fixed in every actor and their every action [13]. In internet economy era, "let fighters who can hear the gunfire command the battle" has made entrepreneurship a source of motivation for the organizational sustainable innovation. Entrepreneurship has become a secret method of innovation in many practical organizations [14].

The literature review of existing studies has pointed out that the premise of enterprise innovation lies in the formation of entrepreneurship [15]. Specifically, scholars have successively explored the impact of entrepreneurship on innovation, such as product or service innovation performance, enterprise innovation performance, and innovation capability $[16,17]$. Enterprises with high entrepreneurship are often able to effectively find new ideas and timely apply innovative thinking to the knowledge resource combination which is needed during the process of improving new product creation $[18,19]$. This is supposed to significantly affect the innovation ability and financial performance. Essentially, there are relatively few studies on the impact of entrepreneurship and enterprises' sustainable innovation capability [5]. Researchers generally regard entrepreneurship as the source of sustainable innovation in enterprises. They consider that entrepreneurship digests and absorbs knowledge and information and accumulates resources through organizational learning and network capabilities [8]. Therefore, organizational learning and knowledge innovation activities are the key to influence the entrepreneurship to achieve sustainable innovation in enterprises [20]. However, the intention to cooperate among the members of the organization is not enough to promote the full development of innovation activities. The sharing behavior of employees needs to be built based on the relationship of mutual trust [21]. Only when sufficient organizational recognition is formed among the members of the organization can individual goals and organizational goals be bound to each other. It enables individual actively contribute or sacrifice their personal interests for the benefit of the organization [22]. So as to achieve the development of enterprise innovation activities [23]. In the digital era, entrepreneurship has gradually appeared in employees as a spiritual trait. Employees carry the important responsibility of identifying opportunities and achieving sustainable innovation. Hence, inspiring individual members of the organization to form a consistent sense of identity is essential for the development of entrepreneurship and the construction of sustainable innovation capability. However, the existing research actually ignores the exploration of the relationship between entrepreneurship and sustainable innovation capability based on organizational identity as the main line, which makes the relationship mechanism between entrepreneurship and sustainable innovation capability still in a vague state. Our research fills this gap and explores the new mechanism of enterprise innovation and development by entrepreneurship in the digital era.

Organizational commitment refers to the consistent tendency of employees due to their unilateral investment in the organization, which reflects the employees' sense of identification with organizational value and organizational culture [24]. Among them, affective commitment refers to the strength of personal identification and participation in the organization and belief and acceptance of the organizational goals and values, as well as the willingness to work hard and stay in the organization; continuance commitment refers to the individual's recognition that she/he will lose the ancillary benefits of existing value once she/he leaves the organization, so she/he has to remain in the organization [24,25]. Enterprises in digital era emphasize the organic unity of organizational interests and employees' work goals. The decentralization of organizational decision-making power conveys important signals of investment to employees [26,27]. Thus, when employees can feel the importance and trust of the organization, they are motivated to build their own 
organizational identification and promote the development of organizational innovation activities. Based on this, this study will mainly examine the impact of entrepreneurship on the sustainable innovation capability and its mechanism of enterprises in digital era and expand the existing research from the following three aspects: first, reveal the causes of enterprises' sustainable innovation capability in digital era from the perspective of entrepreneurship at organizational level; second, reveal the mediating mechanism between the entrepreneurship and the enterprise's sustainable innovation capability from the perspective of organizational commitment; and third, explore the moderating role between entrepreneurship and enterprises' sustainable innovation capability in digital era from the perspective of value fit and perceived organizational support.

\section{Theoretical Background Hypothesis Development}

\subsection{Entrepreneurship and Sustainable Innovation Capability}

Entrepreneurship is a concept with rich semantics, in the research of which, three mainstream schools have been formed: Austrian School, German School, and Neoclassical School. In the Austrian School, scholars have interpreted entrepreneurship in a broad and narrow sense. Broadly speaking, entrepreneurship mainly refers to the ability to withstand uncertain environments. Since the work of ordinary laborers is also highly uncertain, entrepreneurship is considered to be a trait of the personnel involved in the production activities of enterprises, not just owned by entrepreneurs [12,14]. In a narrow sense, entrepreneurship refers to the ability to cope with various risks in the process of realizing production structures and business models $[28,29]$. In the follow-up research, scholars further defined the concept of entrepreneurship. North emphasized in the new institutional economics that the spirit of cooperation is an important source of entrepreneurship [30]. Dolan and Garcia pointed out that entrepreneurship encompasses not only ambition, creativity, and energy but also strong moral principles [31]. Mort et al. pointed out that entrepreneurship needs to create corporate and social benefits [32]. In addition to bearing risks, identifying and utilizing opportunities, and innovating, it should also balance the value of various stakeholders. Although different scholars have not yet unified the concept of entrepreneurship, the core connotation of which has basically reached an agreement, that is, the ability to discover and use opportunities to obtain observable rewards [33]. By summarizing the research of existing scholars, this article believes that entrepreneurship includes five dimensions: innovation, cooperation, active competition, risk-taking, and society-helping [30-32,34,35].

With the application of internet technology, more and more enterprises have realized platform transformation in the digital era. Enterprises can break through the boundary constraints of innovation elements to obtain sustainable innovation capability [36]. Under the cultural atmosphere of openness, empowerment, and being people-oriented, the organization establishes customer-oriented and symbiotic values among members of the organization by providing emotional and instrumental support to employees so that employees can devote themselves to the cultivation of core competitiveness of enterprises in the guidance of consistent goals [24,37]. Entrepreneurship as an important innovation resource of an enterprise has an important impact on the sustainable innovation capability of enterprises. This article makes the following theoretical conjectures on the relationship between entrepreneurship and the enterprises' sustainable innovation capability: First, entrepreneurship emphasizes the spirit of innovation and collaboration, and the transmission of innovation spirit within the enterprise can drive members to break through the existing knowledge system [38]. Enterprises achieve the upgrading of innovative technology through the collaboration between employees and the continuous exchange of explicit knowledge and hidden knowledge. This is the basic guarantee for realizing the sustainable innovation capability of the enterprises [10,39]. Second, when enterprises are facing complex situations, it is beneficial to have an active competition strategy that can formulate forward-looking innovation strategies, flexibly adjust innovative research and development activities according to the changes of the situation. It ensures enterprises' 
long-term innovation and development $[4,6,40]$. Third, the risk-taking in entrepreneurship can fully discover the problems existing in the process of innovation activities. It effectively formulates risk response measures, improves the accuracy and effectiveness of innovation policies, further clarifies innovation goals and directions, and accelerates the construction of internal innovation culture. In order to create a good internal innovation atmosphere, risk-taking entrepreneurship enhances communication among members in the company to achieve improvement of the sustainable innovation capability of the enterprises [41,42]. Finally, the entrepreneurship can regulate the direction of enterprise innovation and development, promote enterprises to fulfill their social responsibilities and value creation activities consistent with social values, and respond positively to social issues [43]. It discovers innovative problems from practice and maintains a keen sense of practical issues to promote the improvement of the sustainable innovation capability of the enterprises. Therefore, this article makes the following hypothesis:

Hypothesis $\mathbf{1}$ (H1). Entrepreneurship has a positive impact on an enterprise's sustainable innovation capability.

\subsection{Entrepreneurship, Organizational Commitment, and Sustainable Innovation Capability}

The concept of organizational commitment was first proposed by Becker, who refers to the consistent tendency of employees due to their unilateral investment in the organization. The author reflects the employees' identification of organizational value and organizational culture [24]. On this basis, Allen and Meyer et al. formed the three-factor model of organizational commitment that are most widely used [44]. Affective commitment is the core of organizational commitment, which mainly refers to employees' substantive emotion toward the organization. It includes organizational goal identification and the employee's sense of pride [45]. Different organizational commitments represent different psychological states of the organization and its employees. They not only imply the loyalty of employees who are willing to stay in the organization but also contain the employees' recognition of organizational value and culture [24].

First, the main purpose of entrepreneurship is to encourage innovation. The organizations with entrepreneurship pay more attention to arousing and strengthening the consistent identity of employees. By building a platform for communication between employees and shaping an open innovation culture and triggering the promotion of employees' affective commitment, employees develop a stronger desire to stay and make substantial contributions to the organization [46].

Second, entrepreneurship means that the organization has a stronger sense of risktaking [41,42]. The decision-making power of leaders in enterprises has been effectively implemented, and employees begin to realize the importance of their own decision-making opinions for the realization of the value objectives of the organization; thus, they show positive innovation behavior based on ownership consciousness and devote themselves to the construction of innovation activities to help the organization obtain the sustainable competitive advantage [47].

Finally, entrepreneurship encourages employees to conduct more cross-departmental cooperation by creating a sharing cooperation atmosphere, which enables the members of the organization to gradually establish their own role orientation in the interaction with the organization and other members, so as to bind the realization of organizational goals and individual values. Higher willingness of risk-taking leads to higher level of creativity $[48,49]$. Existing studies have confirmed the impact of affective commitment on employees' creativity and innovative behavior. They found that employees with high affective commitment usually establish emotional links with the organization, which can improve their ability to anticipate the loss of organizational well-being and thus help to promote their willingness to make self-sacrifice in order to protect the interests of the organization $[24,44,46]$. Swailes found that affective commitment is an important factor in innovation [50]. Employees with high affective commitment tend to find innovative ways 
to solve problems in their work so as to improve the sustainable innovation capability of the organization. Li et al. pointed out that the affective commitment of the organization will promote the transformation of knowledge resources into innovation achievements, so as to improve the innovation ability of the organization [51]. To summarize, this paper makes the following hypotheses:

Hypothesis 2 (H2). Entrepreneurship has a positive impact on affective commitment.

Hypothesis 3 (H3). Affective commitment has a positive impact on the sustainable innovation capability of enterprises.

Hypothesis 4 (H4). Entrepreneurship influences the sustainable innovation capability of enterprises through the mediating role of affective commitment. That is to say, entrepreneurship has a facilitating effect on affective commitment, so as to promote the sustainable innovation capability of enterprises.

Continuance commitment refers to the fact that employees have to stay in the team when they realize the loss of leaving the team. It is a constraint on individual behavior based on the cost of leaving the organization [24]. In fact, employees with high continuance commitment usually think that they are embedded in a certain environment that cannot be chosen, and they are in a psychological experience of "have to" or "must". Although they may not want to stay in the organization, they have to remain in it, because the employees with continuance commitment maintain the employment relationship only through economic exchange [52]. In this situation, enterprises do not encourage employees to undertake any extra work to some extent.

However, in the digital era, the existence of entrepreneurship weakens the traditional employment relationship between the organization and the employees; instead, the relationship between the organization and the employees tends to form a cooperative relationship based on emotion and trust $[8,21]$. The organization with entrepreneurship obtains the emotional identity of employees by establishing universal values, thus forming a common mental model among employees [53]. The purpose of employees' work is no longer simply limited to economic benefits but to whether they can achieve the growth of the organization and enhance their self-worth through joint efforts with others [54]. This process stimulates the employees' responsibility behavior to the organization and makes the employees' willingness to stay in the organization stronger. What's more, entrepreneurship emphasizes taking risks and meeting challenges actively. With the increasingly flat organizational structure, the organization encourages employees to solve problems around customer's needs, and employees are not stuck to the inherent work form of top-down and waiting for instructions [55]. The organization creates more added value for customers by giving employees more decision-making power and growth space, thus reducing the continuance commitment of employees. The innovation and cooperation orientation of entrepreneurship means that the organization supports the cross-functional communication of employees, that is, everyone can become the leader of a project; the employees can obtain emotional support and ability recognition in the interaction with other department members and then perceive their own importance to the organization, so as to make employees improve their work devotion motivation and psychological security, and engage in behaviors beneficial to the organization or team [56]. As a result, employee commitment can be reduced effectively.

On the other hand, most of the existing studies emphasize the negative impact of continuance commitment on employee innovation behavior and organizational innovation performance $[57,58]$. The essential reason is that continuance commitment is an organization-employee relationship based on economic exchange. High continuance commitment conditions mean that employees are more concerned about the gains and losses of existing resources or capabilities. Usually, they are more inclined to choose two kinds of negative behavioral reactions of passive acceptance or obedience, or indifference or 
avoidance, so that they are not willing to engage in risky or innovative behavior $[24,50,57]$. In the digital era, the low continuance commitment of employees means that employees will not be constrained by forced sacrifice and selection difficulties, so that employees can get rid of the worries behind them. Employees will voluntarily participate in the innovation activities of the organization to put their own resources and abilities into the construction process of the core competitive advantage of the organization by exerting their personal creativity and promoting the knowledge interaction within the organization so as to continuously cultivate the sustainable innovation capability of the organization. To summarize, this paper makes the following hypotheses:

Hypothesis $\mathbf{5}$ (H5). Entrepreneurship has a negative impact on continuance commitment.

Hypothesis 6 (H6). Continuance commitment has a negative impact on the sustainable innovation capability of enterprises.

Hypothesis 7 (H7). Entrepreneurship influences the sustainable innovation capability of enterprises through the mediating role of continuance commitment, that is, entrepreneurship has an inhibitory effect on continuance commitment, thus promoting the improvement of the sustainable innovation capability of enterprises.

\subsection{The Moderating Effect of Perceived Organizational Support}

Organizational support theory was formally proposed by Kurtessis et al. on the basis of "organizational justice theory" and "social exchange theory" [59]. Perceived organizational support refers to the extent to which employees feel that the organization attaches importance to their own contributions and benefits. McMillin divided perceived organizational support into emotional support and instrumental support on the basis of Kurtessis' research. Perceived organizational support comes from the employees' perception and view of the organization [60]. Baran et al. further pointed out that the perceived organizational support refers to the idea that employees feel the organization supports their work, cares for their interests, and recognizes their values [61]. It is a comprehensive evaluation and judgment of employees' attitude toward the organization based on their own perception and experience, which determines whether employees can devote themselves to the activities of organizational innovation [62,63]. Some studies believe that perceived organizational support is the premise of employees' organizational commitment [64]. According to the "reciprocity principle" of social exchange theory, high perceived organizational support means that employees fully feel the concern and help of the organization for their investment, which helps to show the entrepreneurship of employees. Employees initiate the consciousness and behavior of active innovation to achieve mutual benefit and symbiosis with the organization [65]. In the process, employees will show stronger responsibility of contribution to the achievement of organizational interests and goals, which urges them to repay the organization with higher organizational commitment and harder work.

What's more, the necessary resources and support are the key to the organization to achieve innovation. The organization provides substantial resource support to employees through empowerment so as to reduce employees' perceptions of innovation risk and ease the relationship embeddedness between organization and employees based on economic exchange. It enables employees to focus on the thinking of customer-oriented solutions so as to improve their self-worth and reduce their continuance commitment $[47,55]$. Existing studies have verified that supportive culture and atmosphere are not only conducive to predict employees' innovative behavior but also contribute to the formation of an organizational atmosphere of trust and cooperation [66]. Perceived organizational support can make employees feel the support, understanding, and recognition of their ability from other members of the organization. By doing so, it produces a series of positive emotional experiences, which can induce employees' continuous cooperative behavior so that employees can obtain more sense of belonging and organizational identity through 
efficient cooperation, interpersonal interaction, and information exchange and ultimately enhance employees' affective commitment. To summarize, this paper makes the following hypotheses:

Hypothesis 8 (H8). Perceived organizational support positively moderates the relationship between entrepreneurship and affective commitment, that is, when the perceived organizational support is stronger, the impact of entrepreneurship on affective commitment will be stronger.

Hypothesis 9 (H9). Perceived organizational support positively moderates the relationship between entrepreneurship and continuance commitment, that is, when the perceived organizational support is stronger, the negative impact of entrepreneurship on continuance commitment will be stronger.

\subsection{The Moderating Effect of Person-Organization Value Fit}

Person-organization value fit refers to the similarity or consistency between individual values of employees and organizational values. It is a criterion for employees to guide work behavior, evaluate work value, and measure whether goals are in line with organizational expectations [67]. Enterprises need to gather the personal goals of all employees so that employees can reach an agreement with the needs of enterprises in terms of beliefs, values, etc. Existing studies have verified the influence of person-organization value fit on employee's work engagement, work attitude, and innovative behavior $[68,69]$. Value fit can strengthen the emotional connection between organization and employees [69]. This study suggests that enterprises generally advocate the value concept of encouraging innovation and symbiosis in digital era [70]. According to the theory of person-environment fit, the fit between individual and environment is helpful to stimulate the individual's positive attitude and behavior [71]. When the person-organization value fit is high, employees can fully understand and practice the organization's fundamental demands for innovation. They actively establish the fundamental connection between their own goals and the realization of organizational values and strive to make up for the gap between themselves and the expectations of the organization so as to form a stronger affective commitment to the organization $[45,46,69]$. At the same time, the role and identity of employees in the organization has changed from "employee" to "entrepreneur" [8,10,12,13]. The organizational value of "employee being the master" releases the spirit of taking risk and taking responsibility of individuals, and the actual working status of employees is improved. They have more independent decision-making power and can solve the enterprise problems through informal team structure and at the same time obtain more sense of achievement in the realization of self-worth promotion [72]. Employees who share the same values with the organization will feel harmonious in the organization. At the same time, they will be more likely to obtain organizational identification and resource support, reduce the uncertainty of employees in innovation activities, and improve their sense of job security $[68,73]$. Therefore, employees can feel the attraction of the organization and choose to stay in the organization by contributing their own creativity and innovation, realizing the common growth with the organization. To summarize, this paper makes the following hypotheses:

Hypothesis 10 (H10). Person-organization value fit positively moderates the relationship between entrepreneurship and affective commitment, that is, when the organizational support is stronger, the positive impact of entrepreneurship on affective commitment will be stronger.

Hypothesis 11 (H11). Person-organization value fit positively moderates the relationship between entrepreneurship and affective commitment, that is, when the organizational support is stronger, the negative impact of entrepreneurship on continuance commitment will be stronger.

The research model of this study is shown in Figure 1. 


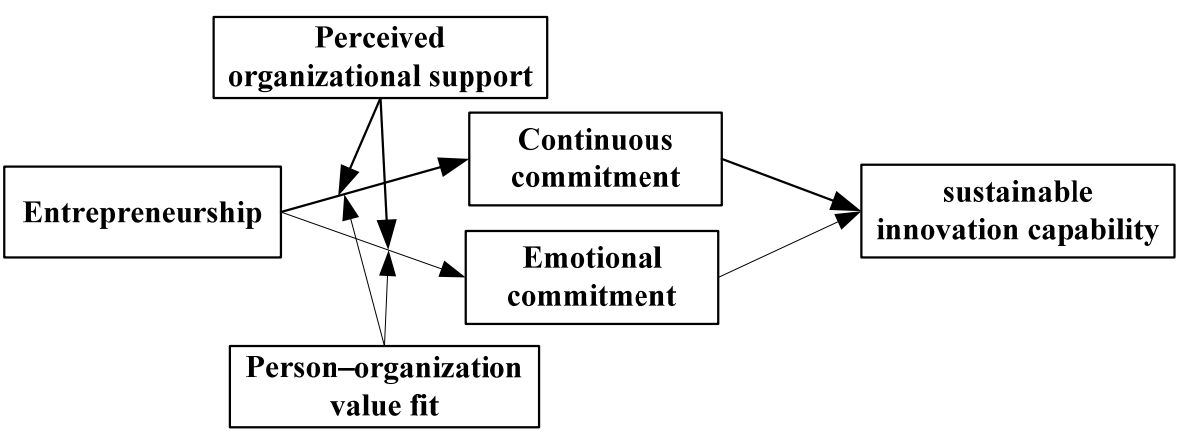

Figure 1. Research model of the study.

\section{Methods}

\subsection{Data Collection}

The sample data of this study comes from the questionnaire survey. In order to improve the representativeness of the sample, enterprises with different natures (including state-owned, private, and joint ventures) from different locations (including Fujian, Guizhou, Hubei, and Jiangsu Province) and different enterprise scales (including less than 50 people, $50-150$ people, and more than 150 people) were selected as samples, since this study is based on the research situation of digital transformation enterprises and regards entrepreneurship as an individual spiritual trait, so that the employees, leaders, and other participants in digital transformation enterprises are selected as the respondents to investigate the actual situation of entrepreneurship, organizational commitment, and organizational sustainable innovation capability of each digital transformation enterprise. Questionnaire distribution and data collection methods include direct door-to-door research, letters, and e-mails. In this study, we randomly selected one employee each from 750 different companies to form a sample of 750 respondents. A total of 750 questionnaires were collected. After screening, it was found that only 387 questionnaires were valid. Therefore, the effective response rate of the questionnaire was $51.6 \%$. After obtaining the sample data, this study analyzes the gender, age, education and seniority of the employee and the nature and the scale of the enterprise. The specific information is shown in Table 1.

Table 1. Descriptive statistics of digital transformation enterprises' employees.

\begin{tabular}{|c|c|c|c|}
\hline Characteristics & Category & Number of People & Proportion \\
\hline \multirow[b]{2}{*}{ Gender } & Male & 208 & $53.75 \%$ \\
\hline & Female & 179 & $46.25 \%$ \\
\hline \multirow{5}{*}{ Age } & 25 years old and below & 117 & $30.23 \%$ \\
\hline & $26-35$ years old & 154 & $39.79 \%$ \\
\hline & $36-45$ years old & 82 & $21.19 \%$ \\
\hline & 46-55 years old & 31 & $8.01 \%$ \\
\hline & 56 years old and above & 3 & $0.78 \%$ \\
\hline \multirow{4}{*}{ Education } & Higher vocational and below & 12 & $3.10 \%$ \\
\hline & Specialist & 73 & $18.86 \%$ \\
\hline & Undergraduate & 225 & $58.14 \%$ \\
\hline & Master's degree and above & 77 & $19.90 \%$ \\
\hline \multirow{4}{*}{ Seniority } & 1 year or less & 12 & $3.10 \%$ \\
\hline & $2-5$ years & 172 & $44.44 \%$ \\
\hline & 6-10 years & 192 & $49.61 \%$ \\
\hline & 11 years and above & 11 & $2.84 \%$ \\
\hline \multirow{4}{*}{ Nature of enterprise } & State-owned enterprise & 124 & $32.04 \%$ \\
\hline & Private enterprise & 183 & $47.29 \%$ \\
\hline & Joint venture & 68 & $17.57 \%$ \\
\hline & Other & 12 & $3.10 \%$ \\
\hline \multirow{3}{*}{ Scale of enterprise } & Less than 50 people & 78 & $20.16 \%$ \\
\hline & 50-150 people & 213 & $55.04 \%$ \\
\hline & 150 people or more & 96 & $24.81 \%$ \\
\hline
\end{tabular}




\subsection{Variable Measures}

This research questionnaire adopted the mature scale that has been studied at home and abroad, and then some of the items were revised in accordance with the research situation, and 80 workers in digital transformational enterprises were invited to conduct pre-surveys, which were revised many times to ensure the reliability and validity of the final questionnaire. The variables were measured by Likert's 5-point scale, with 1 indicating strong disagreement and 5 indicating strong agreement.

The independent variable was entrepreneurship. The design of the entrepreneurship scale was based on Covin and Slevin's understanding of entrepreneurship in terms of innovation [74], proactive competitive attitude, and risk-taking and also absorbed the view of North [30], Mort et al. [32], and Nambisan [8,10], that entrepreneurship should include the spirit of cooperation and the spirit of helping the society. After adding the two dimensions of the sense of cooperation and the spirit of helping the society, there were 25 items in total. Scale items include "actively communicate and communicate with others" and "having a sense of social responsibility and rewarding society".

The mediating variables were affective commitment and continuance commitment. The measurement of affective commitment and continuance commitment mainly drew on the views of Meyer and Allen [44]. Affective commitment mainly included 6 items, such as, "I am willing to spend my future career in the current organization" and "personally, the current organization is of great significance to me". Continuance commitment mainly included 6 items, such as, "now I have to stay in this organization, which is what I hope" and "I have too few choices to consider leaving the organization now".

The moderating variables were perceived organizational support and personorganization value fit. The measurement of perceived organizational support in this paper was based on the scale developed by Kurtessis et al., which includes 8 items [59], such as "the enterprise has effective procedures to deal with and solve the dissatisfaction and opinions from employees" and "employees can understand the enterprise's policy information through various channels of the enterprise". The scale of Edwards and Cable was used to match the values of person-organization value fit [67], and it is more appropriate to use subjective matching for conceptualization and measurement on employees' psychology, attitude, and behavior. Therefore, this study used "the degree to which employees perceive their own values match the values of the organization" to measure the value fit between employees and the organization. For example, "what I value is very similar to what the organization values".

The dependent variable was the sustainable innovation capability. This paper used the scale developed by Song Zhihong and others to measure the enterprise's sustainable innovation capability [75], including 5 items, such as "compared with competitors, organizations can launch new products or services faster".

In addition to the demographic variables of gender, age, education, and seniority, this study also controled the scale and nature of enterprises in terms of the differential effects of these two factors on entrepreneurship and sustainable innovation capability of enterprises.

\subsection{Reliability and Validity of Measurements}

Although this article used mature scales, due to changes in the research situation, this article used SPSS 20.0 to test the reliability of the scales of the research variables involved. Through testing, the results showed that Cronbach's alpha coefficient of entrepreneurship was 0.876; the Cronbach's alpha coefficients of affective commitment and continuance commitment were 0.865 and 0.872 ; the Cronbach's alpha coefficient of enterprise's sustainable innovation capability was 0.814 ; the Cronbach's alpha coefficient of perceived organizational support was 0.817; and the Cronbach's alpha coefficient of person-organization value fit was 0.901 . The above results are all greater than the reference value of 0.7 , indicating that the internal consistency of the scale used in this article is good, and the structure of the scale is stable. 
In addition, this article used AMOS19.0 to verify validity through confirmatory factor analysis. The specific test results are shown in Table 2, below. Through the test, it was found that the test result of the six-factor model in this article is the best $\left(\chi^{2} / \mathrm{df}=1.128\right.$, $\mathrm{CFI}=0.911$, TLI $=0.907$, RMSEA $=0.032$, SRMR $=0.027$ ), and each measurement index is above the standard value, indicating that the distinguishing validity of the variables in this article is good and can continue to carry out subsequent data analysis.

Table 2. Confirmatory factor analysis results $(\mathrm{N}=387)$.

\begin{tabular}{ccccccccc}
\hline Model & Factor Combination & $\chi^{2}$ & df & $\chi^{2} / \mathbf{d f}$ & CFI & TLI & RMSEA & SRMR \\
\hline Model 1 & EP, EC, CC, POS, POVF, OCIC & 86.13 & 79 & 1.09 & 0.92 & 0.91 & 0.031 & 0.022 \\
\hline Model 2 & EP, EC + CC, POS, POVF, OCIC & 347.20 & 91 & 3.82 & 0.89 & 0.87 & 0.069 & 0.053 \\
\hline Model 3 & EP, EC, CC + POS + POVF, OCIC & 577.28 & 94 & 6.14 & 0.87 & 0.86 & 0.075 & 0.071 \\
\hline Model 4 & EP, EC + CC + POS + POVF, OCIC & 708.47 & 93 & 7.62 & 0.86 & 0.83 & 0.084 & 0.077 \\
\hline Model 5 & EP, EC + CC + POS + POVF + OCIC & 891.13 & 97 & 9.18 & 0.83 & 0.81 & 0.097 & 0.082 \\
\hline Model 6 & EP + EC + CC + POS + POVF + OCIC & 1157.58 & 99 & 11.69 & 0.67 & 0.75 & 0.212 & 0.195 \\
\hline
\end{tabular}

Note: Model 1: Six-factor model; Model 2: Five-factor model; Model 3: Four-factor model; Model 4: Three-factor model; Model 5: Two-factor model; Model 6: Single-factor model; EP stands for entrepreneurship; EC stands for affective commitment; CC stands for continuance commitment; POS stands for perceived organizational support; POVF stands for person-organization value fit; OCIC stands for sustainable innovation capability of enterprise.

\subsection{Common Method Variance}

This article took multiple times to collect data and to try to avoid the problem of homologous variance. Harman's single-factor analysis method was used to test whether there was a common method deviation problem. The results of the data showed that a total of 5 factors with eigenvalues greater than 1 were extracted, and the maximum explanatory variance of single factor was $19.227 \%$, which is far less than the reference value of $40 \%$. Therefore, it can be concluded that the data collected in this paper does not have obvious common method deviation problems.

\subsection{Correlation Analysis}

In order to carry out subsequent hypothesis test, this article uses SPSS20.0 to perform correlation analysis on related variables involved. The specific analysis results are shown in Table 3.

Table 3. Correlation analysis $(\mathrm{N}=387)$.

\begin{tabular}{|c|c|c|c|c|c|c|c|c|c|c|c|c|c|c|}
\hline Variable & $\mathbf{M}$ & SD & 1 & 2 & 3 & 4 & 5 & 6 & 7 & 8 & 9 & 10 & 11 & 12 \\
\hline Gender & 0.463 & 0.441 & 1 & & & & & & & & & & & \\
\hline Age & 2.093 & 0.532 & 0.033 & 1 & & & & & & & & & & \\
\hline Edu & 2.948 & 0.526 & -0.109 & 0.153 & 1 & & & & & & & & & \\
\hline Seniority & 2.522 & 0.531 & $0.053 * *$ & 0.032 & 0.134 & 1 & & & & & & & & \\
\hline $\mathrm{EO}$ & 1.917 & 0.597 & -0.062 * & $0.101^{* *}$ & 0.203 & 0.093 & 1 & & & & & & & \\
\hline ES & 2.047 & 0.603 & 0.067 & 0.086 & $-0.097^{*}$ & 0.217 & 0.026 & 1 & & & & & & \\
\hline ENT & 2.615 & 0.512 & 0.133 & -0.034 & 0.214 & 0.088 & 0.156 & 0.102 & 1 & & & & & \\
\hline EC & 3.214 & 0.509 & $0.141^{* *}$ & $0.025^{* *}$ & 0.134 & $0.016^{*}$ & $0.263 *$ & 0.112 & $0.104^{* *}$ & 1 & & & & \\
\hline $\mathrm{CC}$ & 3.103 & 0.511 & 0.181 * & 0.174 & $-0.235^{*}$ & $0.153^{* *}$ & -0.023 & 0.281 * & $-0.117^{* *}$ & $-0.105^{* *}$ & 1 & & & \\
\hline POS & 2.773 & 0.523 & 0.201 & 0.161 & 0.013 & 0.214 & $0.077 * *$ & $0.106^{* *}$ & 0.121 * & $0.089 *$ & $-0.064^{* *}$ & 1 & & \\
\hline PVF & 2.678 & 0.531 & 0.033 & 0.054 & 0.112 & 0.016 & 0.213 & $0.102 * *$ & $0.034^{* *}$ & $0.077^{*}$ & $-0.105^{* *}$ & $0.014^{* *}$ & 1 & \\
\hline OCIC & 2.738 & 0.557 & 0.272 & 0.019 & $0.301^{* *}$ & 0.218 & 0.009 & $0.107^{* *}$ & $0.093^{* *}$ & $0.101^{* *}$ & $-0.216^{* *}$ & $0.113^{* *}$ & $0.079^{* *}$ & 1 \\
\hline
\end{tabular}

Note: ${ }^{*} p<0.05 ;{ }^{* *} p<0.01$. EO stands for nature of enterprise; ES stands for scale of enterprise; ENT stands for entrepreneurship; EC stands for affective commitment; CC stands for continuance commitment; POS stands for perceived organizational support; PVF stands for person-organization value fit; OCIC stands for sustainable innovation capability of enterprise. In "Gender", "Male" = 0, "Female" = 1; in "Age", "25 years old and below" = 1, "26-35 years old" = 2, and so on; in "Education", "Higher vocational and below" = 1, "Specialty" = 2, and so on; in "Seniority", "1 year and less" = 1, "2-5 years" = 2, and so on; in "Nature of enterprise", "State-owned enterprise" = 1, "Private enterprise" $=2$, and so on; in "Scale of enterprise", "Less than 50 people" $=1$, "50-150 people" = 2, and so on. 


\section{Results \\ 4.1. Mediating Effect Test}

This article used Mplus7.4 to test the mediating effect of the theoretical model, and the research results are shown in Tables 4 and 5, below. Through data analysis, it was found that entrepreneurship had a positive effect on the sustainable innovation capability $(\beta=0.132, p<0.001)$, and fitting index of model 1 was $\operatorname{good}(\chi 2 / \mathrm{df}=2.73, \mathrm{CFI}=0.901$, $\mathrm{TLI}=0.903$, RMSEA $=0.044$, SRMR $=0.052)$, so H1 has been verified. Entrepreneurship had a positive impact on affective commitment $(\beta=0.054, p<0.01)$, and the confidence interval at $95 \%$ level was $(-0.098,-0.224)$, which does not include 0 ; therefore, $\mathrm{H} 2$ has been verified. Entrepreneurship had a negative impact on continuance commitment $(\beta=-0.105$, $p<0.01)$, and the confidence interval at $95 \%$ level was $(-0.093,-0.265)$, which does not include 0 ; therefore, $\mathrm{H} 5$ has been verified. Affective commitment had a positive impact on the enterprise's sustainable innovation capability $(\beta=0.139, p<0.01)$ and the confidence interval at $95 \%$ level was $(-0.101,-0.277)$, which does not include 0 , so $\mathrm{H} 3$ has been verified. Continuance commitment had a negative impact on the enterprise's sustainable innovation capability $(\beta=-0.101, p<0.01)$, and the confidence interval at $95 \%$ level was $(-0.013,-0.233)$, which does not include 0 , so H6 has been verified.

Table 4. Test results of main effects and mediating effects.

\begin{tabular}{cccccc}
\hline Effect Relationship & Path & Estimate & SE & 95\% Confidence Interval & Contains 0 \\
\hline \multirow{3}{*}{ Direct effect } & $\mathrm{ENT} \rightarrow$ SIC & $0.132^{* * *}$ & 0.027 & {$[-0.053,-0.112]$} & No \\
\cline { 2 - 6 } & $\mathrm{NET} \rightarrow \mathrm{EC}$ & $0.054^{* *}$ & 0.035 & {$[-0.098,-0.224]$} & No \\
\cline { 2 - 6 } & $\mathrm{EC} \rightarrow \mathrm{SIC}$ & $0.139^{* * *}$ & 0.104 & {$[-0.101,-0.277]$} & No \\
\cline { 2 - 6 } & $\mathrm{NET} \rightarrow \mathrm{CC}$ & $-0.105^{* *}$ & 0.078 & {$[-0.093,-0.265]$} & No \\
\hline \multirow{2}{*}{ Indirect effect } & $\mathrm{CC} \rightarrow \mathrm{SIC}$ & $-0.101^{* *}$ & 0.046 & {$[-0.013,-0.233]$} & No \\
\cline { 2 - 6 } & $\mathrm{ENT} \rightarrow \mathrm{EC} \rightarrow$ SIC & $0.043^{* *}$ & 0.055 & {$[-0.021,-0.179]$} & No \\
\hline
\end{tabular}

Note: ${ }^{* *} p<0.01 ;{ }^{* *} p<0.001$. ENT stands for entrepreneurship; EC stands for affective commitment; CC stands for continuance commitment; SIC stands for sustainable innovation capability of enterprises.

Table 5. Fitting index of structural equation model for mediating effects.

\begin{tabular}{ccccccc}
\hline Model & $\chi^{2}$ & df & CFI & TLI & RMSEA & SRMR \\
\hline Direct effect & 212.71 & 78 & 0.901 & 0.903 & 0.044 & 0.052 \\
\hline Full mediating effect: affective commitment & 388.67 & 79 & 0.897 & 0.899 & 0.063 & 0.074 \\
\hline Full mediating effect: continuance commitment & 403.11 & 77 & 0.885 & 0.876 & 0.079 & 0.083 \\
\hline Partial mediating effect: affective commitment & 107.24 & 83 & 0.903 & 0.904 & 0.021 & 0.033 \\
\hline Partial mediating effect: continuance commitment & 112.59 & 81 & 0.902 & 0.907 & 0.014 & 0.027 \\
\hline Standard Model Reference Index & - & - & $>0.9$ & $>0.9$ & $<0.08$ & $<0.08$ \\
\hline
\end{tabular}

When both entrepreneurship and affective commitment were included in the model, it found that the indirect effect of affective commitment was 0.053 , and the confidence interval at $95 \%$ level was $(-0.021,-0.179)$, which does not include 0 , so H4 has been verified. When both entrepreneurship and continuance commitment were included in the model, it found that the indirect effect of continuance commitment was -0.067 , and the confidence interval at $95 \%$ level was $(-0.008,-0.115)$, which does not include 0 . Therefore, H7 has been verified.

In order to further test whether the affective commitment and continuance commitment are partial or full mediators between entrepreneurship and an enterprise's sustainable innovation capability, this article compared the fit index of different models (see Table 5). Combined with the above fitting index judgment, fit index of partial mediator model was 
better than the full mediator model. Thus, affective commitment and continuance commitment play a partial mediating role between entrepreneurship and sustainable innovation capability of enterprises. Therefore, $\mathrm{H} 4$ and $\mathrm{H} 7$ have been partially verified.

\subsection{Moderating Effect Test}

This article used SPSS20.0 to test the moderating effect of perceived organizational support and person-organization value fit. The results of moderating effect test are shown in Table 6. When perceived organizational support and the interaction between perceived organizational support and entrepreneurship were included in the analysis model of entrepreneurship-affective commitment, it was found that entrepreneurship had a positive impact on affective commitment, perceived organizational support had a positive impact on affective commitment, and the interaction between the two had a positive impact on affective commitment $(\beta=0.324, p<0.01 ; \beta=0.387, p<0.05 ; \beta=0.497, p<0.01)$. When person-organization value fit and the interaction between person-organization value fit and entrepreneurship were included in the analysis model of entrepreneurship-affective commitment, it was found that entrepreneurship had a positive impact on affective commitment, and person-organization value fit had a positive impact on affective commitment, and the interaction between the two had a positive impact on affective commitment $(\beta=0.226, p<0.01 ; \beta=0.365, p<0.05 ; \beta=0.382, p<0.01)$. The data analysis showed that perceived organizational support and person-organization value fit played positive moderating roles between entrepreneurship and affective commitment, so H8 and H10 have been verified.

Table 6. Test results of moderating effect.

\begin{tabular}{|c|c|c|c|c|c|c|c|c|}
\hline \multirow{2}{*}{ Variable } & \multicolumn{4}{|c|}{ EC } & \multicolumn{4}{|c|}{$\mathrm{CC}$} \\
\hline & Model 1 & Model 2 & Model 3 & Model 4 & Model 5 & Model 6 & Model 7 & Model 8 \\
\hline Gender & 0.213 & 0.117 * & 0.126 & -0.211 & 0.209 & 0.203 & $-0.201 *$ & 0.197 \\
\hline Age & 0.056 & 0.063 & -0.078 & 0.073 & -0.077 & 0.062 & 0.071 & 0.068 \\
\hline Education & $0.121 * *$ & $0.109 * *$ & $0.103^{* *}$ & $0.105 * *$ & $0.120^{* *}$ & $-0.131^{* *}$ & $0.127^{* *}$ & $0.118^{* *}$ \\
\hline Seniority & 0.087 & -0.065 & 0.061 & 0.077 * & 0.053 & 0.049 & 0.032 & 0.055 \\
\hline Nature of enterprise & 0.018 & 0.021 & 0.037 & -0.022 & 0.027 & -0.032 & 0.017 & 0.019 \\
\hline Scale of enterprise & $0.037^{* *}$ & $0.043^{* *}$ & $0.051^{* *}$ & $0.025^{* *}$ & $0.033^{* *}$ & $0.036^{* *}$ & $0.027^{* *}$ & $0.029^{* *}$ \\
\hline ENT & & $0.054^{*}$ & 0.324 * & $0.226 *$ & & $-0.105^{* *}$ & $-0.153^{* *}$ & $-0.289^{* *}$ \\
\hline POS & & & 0.387 * & & & & -0.203 & \\
\hline PVF & & & & $0.365 *$ & & & & $-0.039 *$ \\
\hline ENT*POS & & & $0.497^{* *}$ & & & & 0.112 & \\
\hline $\mathrm{ENT}^{* \mathrm{PVF}}$ & & & & $0.382 * *$ & & & & $0.497 * *$ \\
\hline $\mathrm{R}^{2}$ & 0.01 & 0.05 & 0.13 & 0.21 & 0.01 & 0.09 & 0.13 & 0.28 \\
\hline$\Delta \mathrm{R}^{2}$ & 0.01 & 0.07 & 0.15 & 0.18 & 0.01 & 0.07 & 0.012 & 0.24 \\
\hline F & 1.02 & 5.23 & 10.17 & 14.36 & 3.244 & 8.116 & 8.073 & 9.52 \\
\hline
\end{tabular}

Note: ${ }^{*} p<0.05 ;{ }^{* *} p<0.01$; ENT stands for entrepreneurship; EC stands for affective commitment; CC stands for continuance commitment; POS stands for perceived organizational support; PVF stands for person-organization value fit.

When perceived organizational support and the interaction between perceived organizational support and entrepreneurship were included in the analysis model of entrepreneur ship-continuance commitment, it was found that entrepreneurship had a negative impact on the continuance commitment, while perceived organizational support had no significant impact on the continuance commitment, and the interaction between the two had no significant impact on the continuance commitment $(\beta=-0.153, p<0.01 ; \beta=-0.203$, ns; $\beta=0.112$, ns). The data analysis showed that the moderating effect of perceived organiza- 
tional support between entrepreneurship and continuance commitment was not significant, so H9 has not been verified; when the person-organization value fit and the interaction between person-organization value fit and entrepreneurship were included in the analysis model of entrepreneurship-continuance commitment, it was found that entrepreneurship had a negative impact on the continuance commitment, person-organization value fit had a negative impact on continuance commitment, and the interaction between the two had a positive impact on continuance commitment $(\beta=-0.289, p<0.01 ; \beta=-0.039, p<0.05$; $\beta=0.497, p<0.01$ ). The data analysis showed that person-organization value fit played a positive moderating role in the relationship between entrepreneurship and continuance commitment, so $\mathrm{H} 11$ has been verified.

\section{Discussions and Conclusions}

\subsection{Conclusion and Theoretical Contribution}

Entrepreneurship has a positive impact on the sustainable innovation capability of enterprises, which is basically consistent with the conclusions of previous studies $[16,18]$. One of the major contributions of this article is the focus on the overall connotation of entrepreneurship and the sustainable innovation capability of enterprises. The data test confirmed, once again, that entrepreneurship is a complex, multidimensional concept $[8,10,12,13]$. At the same time, entrepreneurship is not a spiritual characteristic of entrepreneurs but an overall attribute that all employees within the enterprise can possess [76]. There are many factors that affect enterprise innovation in digital era, but it is still difficult to ensure the improvement of the sustainable innovation capability of enterprises $[7,16]$. Starting from the multidimensional concept of entrepreneurship, it is possible to explore the complex causes of sustainable innovation capability of enterprises and provide theoretical guarantee for the sustainable innovation development of enterprises.

Organizational commitment is an important transmission mechanism from entrepreneur ship to sustainable innovation capability, in which affective commitment plays a positive role, while continuance commitment plays a negative role. The enterprise's continuous innovation capability needs not only the stability of employees $[24,25,44]$ but also the high level of employees' input [45]. Entrepreneurship can promote the generation of positive emotions of employees to the organization and can inhibit the situation that employees stay in the enterprise because they have not found better job opportunities [46]. In addition, it also shows that, in order to improve the sustainable innovation capability, enterprises should pay attention to the work needs of employees, cultivate employees' affective commitment, and actively avoid the generation of employees' continuance commitment.

The perceived organizational support plays a moderating role in entrepreneurship and organizational commitment in digital era. When the degree of organizational support is high, the positive effect of entrepreneurship on affective commitment is more obvious, and vice versa; when the degree of perceived organizational support is strong, the effect of entrepreneurship on continuance commitment is not significant (as shown in Figure 2). When perceived organizational support is high, employees can feel the support from the organization, increase their sense of ownership in the organization, and increase their affective commitment to the organization [77]. However, when facing the employees with continuance commitment, the employees pay less attention to perceived organizational support, that is to say, the moderating effect of perceived organizational support on entrepreneurship and continuance commitment is very weak, which is consistent with the data analysis results of this study. 


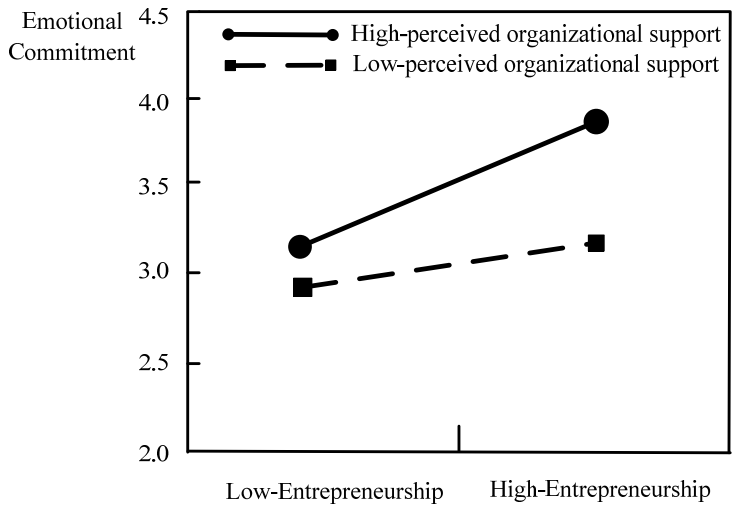

Figure 2. The moderating effect of perceived organizational support.

The person-organization value fit plays a moderating role in entrepreneurship and organizational commitment in platform enterprises. When the degree of person-organization value fit is high, the positive effect of entrepreneurship on affective commitment is more obvious, and vice versa; when the degree of person-organization value fit is high, the negative effect of entrepreneurship on continuance commitment is more obvious, and vice versa (as shown in Figure 3). In the digital era, individuals are more focused on their own value realization. When organizational values and employee values are aligned, employees can improve their work attitudes and commitment, thereby increasing their emotional commitment and reducing their ongoing commitment $[68,69]$. Furthermore, in the digital era, enterprises should focus on collaborative development with their employees. The same or similar values are the basis for collaboration, which also validates the importance of symbiotic values emphasized by many scholars [70].
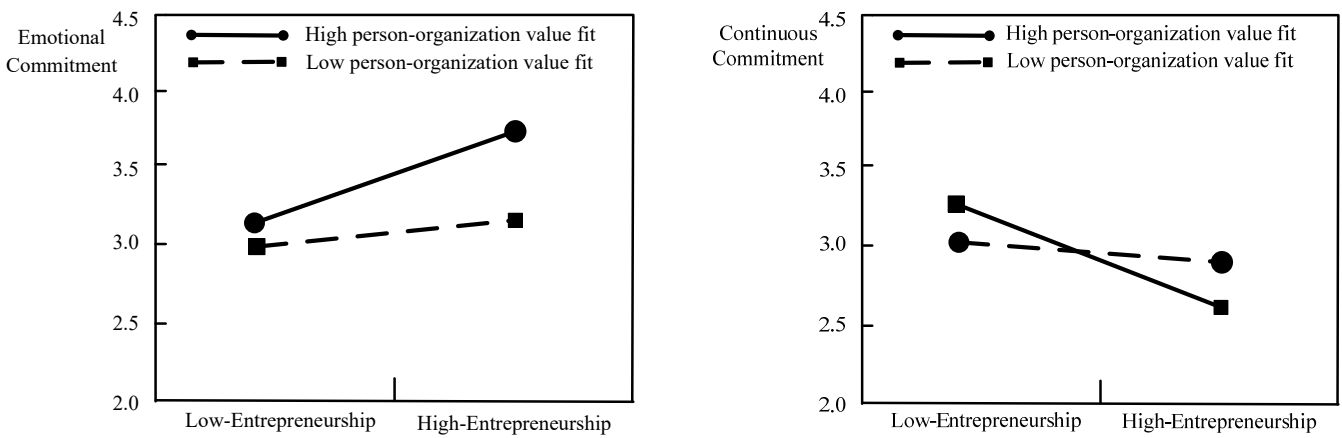

Figure 3. The moderating effect of person-organization value fit.

\subsection{Managerial and Social Implications}

The theoretical analysis and empirical conclusions of this article have important practical implications:

The entrepreneurship of the members in the organizations should be vigorously cultivated, the continuous knowledge spillover effect brought by the entrepreneurship should be given full play, and the sustainable innovation capability of the enterprise should be further improved. First of all, the autonomy and innovation potential of employees have been released to a greater extent in a digital transformational enterprise. However, the discreteness of individual employees requires the enterprise to establish an overall entrepreneurial atmosphere within the whole organization, which can integrate employees with the common innovation goal as the guidance and does not destroy the employees' autonomy and innovation potential [1,2,6]. Therefore, enterprises should pay attention to the factors that affect the emergence and stable functioning of employee entrepreneurship in the organization. For example, enterprises should establish flexible organizational structure, increase the flexibility of employees' work, guide the establishment of employee 
entrepreneurship team with goals, establish flexible human resources management system, encourage employees to communicate and communicate throughout the enterprise platform, etc. Secondly, the severe market environment faced by enterprises in digital era puts forward higher requirements for the acquisition of an enterprise's sustainable innovation capability, so it should continue to pay attention to the positive role of employees' affective commitment to the organization, not only to maintain the stability of employees but also to improve the innovation efficiency of employees [6,9]. In terms of the improvement of an employee organization's commitment, enterprises should pay attention to establish their own development goals in collaboration with employees, establish fault tolerance mechanism, and encourage employees to innovate, but also stimulate employees' spirit of risk-taking.

When making relevant policies or measures to provide work or family support for employees, enterprises should pay attention to the premise that employees have affective commitment to the organization. Therefore, enterprises should pay attention to the cultivation of employees' affective commitment while improving their support for employees. Enterprises can improve employees' affective commitment through various management activities, the construction of benefit distribution mechanism, and the decentralization of decision-making power $[37,47]$. However, if employees have a weak sense of belonging to the organization and even work in the current enterprise just because there are no better job choice opportunities, then any organizational support measures will play a small role $[24,57,58]$.

According to the principle of person-organization fit, enterprises should pay attention to those people who are consistent with the organizational values when they are recruiting or selecting personnel. When the people-organization values are consistent, employees can produce more organizational citizenship behavior [59,69]. However, on the contrary, enterprises also need to take certain measures, such as decomposing customer needs, allowing employees to actively participate in the design of demand satisfaction scheme and decision-making, so that employees and the value pursuit of the organization are consistent. After a long period of running-in, more consistent values will naturally be formed $[1,2,54,58]$.

\subsection{Limitations and Future Research}

There are still some limitations in this study: First, this article assumes entrepreneurship as a spiritual trait that generally exists in internal groups of enterprises in digital era, but in fact, the connotation and extension of entrepreneurship are not scientifically standardized. With the continuous change of business environment, the essence and connotation of entrepreneurship as a product of coevolution with the development of organization and society are also enriched. The follow-up research can try to use qualitative research methods to explore the essence and connotation of entrepreneurship and then grasp the development law of entrepreneurship so as to make the research of entrepreneurship more in line with the needs of the times. Second, the study uses cross-sectional data in data collection and cannot strictly test the causal relationship between variables, especially the relationship between entrepreneurship and organizational commitment. Therefore, in the future research, the longitudinal research design can be used to obtain multi-time data to avoid the causal relationship between variables. Third, this study only discusses the effect of entrepreneurship on the sustainable innovation capability of platform enterprises. However, the existing literature has emphasized that enterprise innovation activities have emerged to the level of network ecology. The change of the business model of enterprises mainly based on digital crowdsourcing has changed the nature of employment relationship and changed the subject and scope of organizational commitment. Therefore, future research can try to explore the specific performance of entrepreneurship and sustainable innovation capability in a crowdsourcing situation and then enrich the research system of entrepreneurship and sustainable innovation capability. Fourth, this study focuses on the perspective of internal activities of the organization and identifies the moderating role 
of the endogenous factors of value fit and perceived organizational support. However, both the carrier of entrepreneurship and the sustainable innovation capability of enterprises are actually inseparable from the active participation of customers to some extent, that is, customers can not only reflect the characteristics of entrepreneurship but also can actively participate in the alleviation of value creation and contribute to the sustainable innovation capability of enterprises. Therefore, future research can attempt to focus on the influence mechanism of the relationship between entrepreneurship and sustainable innovation capability from the perspective of customers.

Author Contributions: All authors contributed equally in this research work. All authors have read and agreed to the published version of the manuscript.

Funding: This work was partially supported by the Funds for the Central Universities (No. 2020QN74), the Cooperative Education Program of Ministry of Education (201802258082), the Social Science Project of Shenyang (SYSK2019-01-07), and the "Chinese traditional culture and management" project of Northeast University IMBA all-English course construction funding project.

Institutional Review Board Statement: The study was conducted according to the guidelines of the Declaration of Helsinki. The review board of North eastern University exempted the research for ethical approval, as it is a survey-based study. The study obtained the consent of the employees working in digital transformation enterprises and they filled the questionnaires willingly.

Informed Consent Statement: Informed consent was obtained from all subjects involved in the study.

Data Availability Statement: The original data is provided by all the authors. If there are relevant research needs, the data can be obtained by sending an email to the corresponding author. Please indicate the purpose of the research and the statement of data confidentiality in the email.

Conflicts of Interest: The authors declare no conflict of interest.

\section{References}

1. Castro, G.; Fernández, M.; Colsa, N.U. Unleashing the convergence amid digitalization and sustainability towards pursuing the Sustainable Development Goals (SDGs): A holistic review. J. Clean Prod. 2021, 280, 122204. [CrossRef]

2. Sachs, J.D.; Schmidt-Traub, G.; Mazzucato, M. Six Transformations to achieve the Sustainable Development Goals. Nat. Sustain. 2019, 2, 805-814. [CrossRef]

3. Macfeely, S. The Big (data) Bang: Opportunities and Challenges for Compiling SDG Indicators. Glob. Policy 2019, 10, 121-133. [CrossRef]

4. Gouvea, R.; Raul, D.; Kapelianis, S. Assessing the nexus of sustainability and information \& communications technology. Technol. Forecast. Soc. Chang. 2018, 130, 39-44.

5. Nambisan, S. Architecture vs. ecosystem perspectives: Reflections on digital innovation. Inf. Organ. 2018, 28, 104-106. [CrossRef]

6. Nambisan, S.; Lyytinen, K.; Majchrzak, A.; Song, M. Digital innovation management: Reinventing innovation management research in a digital world. MIS Q. 2017, 41, 223-238. [CrossRef]

7. Yoo, Y.; Henfridsson, O.; Lyytinen, K. The new organizing logic of digital innovation: An agenda for information systems research. Inf. Syst. Res. 2010, 21, 724-735. [CrossRef]

8. Nambisan, S. Digital Entrepreneurship: Toward a Digital Technology Perspective of Entrepreneurship. Entrep. Theory Pract. 2017, 41, 1-27. [CrossRef]

9. Yoo, Y.; Boland, R.J.; Lyytinen, K.; Majchrzak, A. Organizing for Innovation in the Digitized World. Organ Sci. 2012, 23, 1398-1408. [CrossRef]

10. Nambisan, S.; Wright, M.; Feldman, M. The digital transformation of innovation and entrepreneurship: Progress, challenges and key themes. Res. Policy 2019, 48, 103773. [CrossRef]

11. Wohlgemuth, V.; Wenzel, M.; Berger, E.S.C. Dynamic capabilities and employee participation: The role of trust and informal control. Eur. Manag. J. 2019, 37, 760-771. [CrossRef]

12. Sun, L.; Zhu, R.; Zhang, Y.L. Entrepreneurship: A comparative perspective based on system and history. Foreign Ecol. Environ. Manag. 2019, 41, 3-16.

13. De Soto, J.H. Socialism, Economic Calculation, and Entrepreneurship (New Thinking in Political Economy); Edward Elgar: Cheltenham, UK, 2010.

14. Dong, S.Y.; Qiu, G.D. Research on the Transformation of Enterprise Sustainable Innovation Development From Schumpeter to Drucker. J. Commun. Econ. 2017, 8, 108-110.

15. Bodrožic, Z.; Adler, P.S. The Evolution of Management Models: A Neo-Schumpeterian Theory. Adm. Sci. Q. 2018, 63, 85-129. [CrossRef] 
16. Sulistyo, H.; Siyamtinah, S.H. Innovation Capability of SMEs Through Entrepreneurship, Marketing Capability, Relational Capital and Empowerment. Asia Pac. Manag. Rev. 2016, 21, 196-203. [CrossRef]

17. Chebo, A.K.; Wubatie, Y.F. Commercialisation of technology through technology entrepreneurship: The role of strategic flexibility and strategic alliance. Technol. Anal. Strateg. Manag. 2021, 33, 414-425. [CrossRef]

18. Keld, L.; Ammon, S. Open for Innovation: The Role of Openness in Explaining Innovation Performance Among U.K. Manufacturing Firms. Strateg. Manag. J. 2006, 27, 131-150.

19. Schoemaker, P.J.H.; Sohvi, H.; Teece, D. Innovation, dynamic capabilities, and leadership. Calif. Manag. Rev. 2018, 61, 15-42. [CrossRef]

20. Mao, L.H.; Wang, L.L.; Fang, L. An Empirical Study on the Impact of Entrepreneurship on Enterprise Performance-Based on the Intermediary Effect of Organizational Learning and Organizational Innovation. East China Ecol. Manag. 2016, 30, 148-152.

21. Wallace, J.C.; Butts, M.M.; Johnson, P.D. A multilevel model of employee innovation: Understanding the effects of regulatory focus, thriving, and employee involvement climate. J. Manag. 2016, 42, 982-1004. [CrossRef]

22. Kelman, H.C. Compliance, Identification, and Internalization: Three Processes of Attitude Change. J. Confl. Resolut. 1958, 2, 51-60. [CrossRef]

23. Connelly, C.E.; Kelloway, E.K. Predictors of Employees' Perceptions of Knowledge Sharing Cultures. Leadersh. Org. Dev. J. 2003, 24, 294-301. [CrossRef]

24. Iqbal, S.; José Moleiro, M.; Mário, N.M. Linking Entrepreneurial Orientation with Innovation Performance in SMEs; the Role of Organizational Commitment and Transformational Leadership Using Smart PLS-SEM. Sustainability 2021, 13, 4361. [CrossRef]

25. Kanter, R.M. Commitment and Social Organization: A Study of Commitment Mechanisms in Utopian Communities. Am. Sociol. Rev. 1968, 33, 499-517. [CrossRef]

26. Carson, J.B.; Tesluk, P.E.; Marrone, J.A. Shared Leadership in Teams: An Investigation of Antecedent Conditions and Performance. Acad. Manag. J. 2007, 50, 1217-1234.

27. Wei, Y.S.; Frankwick, G.L.; Nguyen, B.H. Should Firms Consider Employee Input in Reward System Design? The Effect of Participation on Market Orientation and New Product Performance. J. Prod. Innov. Manag. 2012, 29, 546-558.

28. Yu, Y.; Hu, X.; Wang, Y. A Patulous Progress: International Entrepreneurship Effects on Chinese Born-Global Firm Performance. Sustainability 2020, 12, 5508. [CrossRef]

29. Mises, L. Human Action: A Treatise on Economics; Yale University: New Haven, CT, USA, 1949.

30. North, D.C. Institutions. J. Econ. Perspect. 1991, 5, 97-112. [CrossRef]

31. Dolan, S.; Garcia, S. Managing by Values. Eur. Bus Forum 2008, 21, 101-117.

32. Mort, G.S.; Weerawardena, J.; Carnegie, K. Social Entrepreneurship: Towards Conceptualisation. Int. J. Nonprofit Volunt. Sect. Mark. 2003, 8, 76-88. [CrossRef]

33. Hegde, D.; Tumlinson, J. Information Frictions and Entrepreneurship. Strateg. Manag. J. 2021, 42, 491-528. [CrossRef]

34. Vellani, S. Redefining Innovation and Entrepreneurship. Glob. Focus EFMD Bus. Mag. 2021, 15, 1-6.

35. Leunbach, D. Entrepreneurship as a family resemblance concept: A Wittgensteinian approach to the problem of defining entrepreneurship. Scand. J. Manag. 2021, 37, 101141. [CrossRef]

36. Waeal, J. Managing Changes in Service Oriented Virtual Organizations: A Structural and Procedural Framework to Facilitate the Process of Change. J. Electron. Commer. Organ. 2017, 10, 59-83.

37. Radoslaw, N. Developing Serving Culture: Focus on Workplace Empowerment. Empl. Relat. 2019, 41, 1312-1329.

38. Salvato, C.; Vassolo, R. The sources of dynamism in dynamic capabilities. Strateg. Manag. J. 2018, 39, 1728-1752. [CrossRef]

39. Shaher, A.; Ali, K. The effect of entrepreneurial orientation on innovation performance: The mediation role of learning orientation on Kuwait SME. Manag. Sci. Lett. 2020, 10, 3811-3820. [CrossRef]

40. Rodrigo-Alarcón, J.; García-Villaverde, P.M.; Ruiz-Ortega, M.J. From social capital to entrepreneurial orientation: The mediating role of dynamic capabilities. Eur. Manag. J. 2018, 36, 195-209. [CrossRef]

41. Tang, G.; Chen, Y.; Jin, J. Entrepreneurial orientation and innovation performance: Roles of strategic HRM and technical turbulence. Asia Pac. J. Hum. Resour. 2015, 53, 163-184. [CrossRef]

42. Nakku, V.B.; Agbola, F.W.; Miles, M.P.; Mahmood, A. The interrelationship between SME government support programs, entrepreneurial orientation, and performance: A developing economy perspective. J. Small Bus. Manag. 2019, 58, 2-31. [CrossRef]

43. Lyon, D.W.; Lumpkin, G.T.; Dess, G.G. Enhancing entrepreneurial orientation research: Operationalizing and measuring a key strategic decision-making process. J. Manag. 2000, 26, 1055-1085. [CrossRef]

44. Allen, N.J.; Meyer, J.P. The Measurement and Antecedents of Affective, Continuance and Normative Commitment to the Organization. J. Occup. Psychol. 1990, 63, 1-18. [CrossRef]

45. Wang, X. Work-Related Flow: The Development of a Theoretical Framework Based on the High Involvement HRM Practices with Mediating Role of Affective Commitment and Moderating Effect of Emotional Intelligence. Front. Psychol. 2020, 11, 564444. [CrossRef] [PubMed]

46. Kim, H.S.; Baik, K.B.; Kim, J.H. Mediating Effects of Affective commitment between Downward Benevolence and Team Satisfaction \& Team Innovative Behavior. J. Korea Contents Assoc. 2015, 15, 425-433.

47. Muzamil, N.M.; Ibrahim, T.; Neetu, C. Managing open innovation: The roles of empowering leadership and employee involvement climate. Manag. Decis. 2018, 57, 703-723. 
48. Grand, J.A.; Braun, T.; Kuljanin, G.; Kozlowski, S.W.; Chao, G.T. The dynamics of team cognition: A process-oriented theory of knowledge emergence in teams. J. Appl. Psychol. 2016, 101, 1353-1385. [CrossRef]

49. Farmer, S.M.; Van Dyne, L.; Kamdar, D. The contextualized self: How team-member exchange leads to coworker identification and helping OCB. J. Appl. Psychol. 2015, 100, 583-595. [CrossRef]

50. Swailes, S. Goals, Creativity and Achievement: Commitment in Contemporary Organizations. Creat. Innov. Manag. 2000, 9, 185-194. [CrossRef]

51. Li, W.; Sun, R.; Liang, F. The effect of organizational emotional capability on product innovation performance of S\&T enterprises under dynamic environment: A multiple moderated mediation model. J. Indus. Engin. Manag. 2020, 34, 50-59.

52. Galanaki, E.; Ziderman, A. Effects of employee benefits on affective and continuance commitment during times of crisis. Int. J. Manpow. 2019, 41, 220-238. [CrossRef]

53. Fallon-Byrne, L.; Harney, B. Microfoundations of dynamic capabilities for innovation: A review and research agenda. Irish. J. Manag. 2017, 36, 21-31. [CrossRef]

54. Susnienè, D.; Vanagas, P. Development of Stakeholder Relationships by Integrating Their Needs into Organization's Goals and Objectives. Eng. Econ. 2015, 48, 5-21.

55. Branstad, A.; Solem, B.A. Emerging theories of consumer-driven market innovation, adoption, and diffusion: A selective review of consumer-oriented studies. J. Bus. Res. 2020, 116, 561-571. [CrossRef]

56. Kwon, C.K.; Han, S.H.; Nicolaides, A. The impact of psychological safety on transformative learning in the workplace: A quantitative study. J. Workplace Learn. 2020, 32, 533-547. [CrossRef]

57. Jafri, M.H. Organizational Commitment and Employee's Innovative Behavior: A Study in Retail Sector. J. Manag. Res. 2010, 10, 62-68.

58. Han, Y.; Yang, B.Y.; Zhang, P.C. Organizational Commitment Leads to Innovation: The Moderating Effect of Goal Orientation. Stud. Sci. Sci. 2011, 29, 127-137.

59. Kurtessis, J.N.; Eisenberger, R.; Ford, M.T. Perceived Organizational Support: A Meta-Analytic Evaluation of Organizational Support Theory. J. Manag. 2017, 43, 1854-1884. [CrossRef]

60. Michael, M.; Kevin, E.; Cheng, D. Meta-analytic and multiwave comparison of emotional support and instrumental support in the workplace. J. Occup. Health Psychol. 2019, 24, 387-409.

61. Baran, B.E.; Shanock, L.R.; Miller, L.R. Advancing Organizational Support Theory into the Twenty-First Century World of Work. J. Bus. Psychol. 2012, 27, 123-147. [CrossRef]

62. Rich, B.L.; Lepine, J.A.; Crawford, E.R. Job Engagement: Antecedents and Effects on Job Performance. Acad. Manag. J. 2010, 53, 617-635. [CrossRef]

63. Sun, J.M.; Lu, X.X.; Sun, J.Q. The Relationship Between Perceived Organizational Support and Work Engagement and Its Boundary Conditions. J. Manag. Sci. 2015, 28, 93-102.

64. Stinglhamber, F.; Vandenberghe, C. Favorable Job Conditions and Perceived Support: The Role of Organizations and Supervisors. J. Appl. Soc. Psychol. 2006, 34, 1470-1493. [CrossRef]

65. Yang, X.; Zhao, K.; Tao, X. Developing and Validating a Theory-Based Model of Crowdfunding Investment IntentionPerspectives from Social Exchange Theory and Customer Value Perspective. Sustainability 2019, 11, 2525. [CrossRef]

66. Collins, S. Knowledge Exchange and Combination: The Role of Human Resource Practices in the Performance of High-technology Firms. Acad. Manag. J. 2006, 49, 544-560. [CrossRef]

67. Edwards, J.R.; Cable, D.M. The Value of Value Congruence. J. Appl. Psychol. 2009, 94, 654-677. [CrossRef] [PubMed]

68. Lauver, K.J.; Kristofbrown, A.L. Distinguishing Between Employees' Perceptions of Person-job and Person-organization Fit. J. Vocat. Behav. 2001, 59, 454-470. [CrossRef]

69. Dahleez, K.A.; Aboramadan, M.; Bansal, A. Servant Leadership and Affective Commitment: The Role of Psychological Ownership and Person-Organization Fit. Int. J. Organ. Anal. 2020, 29, 493-511. [CrossRef]

70. Warner, K.S.; Wager, M. Building Dynamic Capabilities for Digital Transformation: An Ongoing Process of Strategic Renewal. Long Range Plan. 2019, 52, 326-349. [CrossRef]

71. Shalley, C.E.; Gilson, L.; Blum, T.C. Matching Creativity Requirements and the Work Environment: Effects on Satisfaction and Intentions to Leave. Acad. Manag. J. 2000, 43, 215-223.

72. Porter, L.W.; Steers, R.M.; Mowday, R.T. Organizational Commitment, Job Satisfaction, and Turnover Among Psychiatric Technicians. J. Appl. Psychol. 1973, 59, 603-609. [CrossRef]

73. Lara, Z. Should faith and hope be included in the employees' agenda? Linking PO fit and citizenship behavior. J. Manag. Psychol. 2008, 23, 73-88. [CrossRef]

74. Covin, J.G.; Slevin, D.P. A Conceptual Model of Entrepreneurship as Firm Behavior. Entrep. Theory Pract. 2009, 16, 7-26. [CrossRef]

75. Song, Z.H.; Chen, S.; Fan, L.B. An empirical study on the relationship between knowledge characteristics, knowledge sharing and enterprise innovation ability. Stud. Sci. Sci. 2010, 28, 597-604.

76. Alsharo, M.; Gregg, D.; Ramirez, R. Virtual team effectiveness: The role of knowledge sharing and trust. Inf. Manag. 2016, 54, 479-490. [CrossRef]

77. Vandenberghe, C.; Panaccio, A.; Bentein, K. Time-based differences in the effects of positive and negative affectivity on perceived supervisor support and organizational commitment among newcomers. J. Organ. Behav. 2019, 40, 264-281. [CrossRef] 